\title{
Vital Signs: Alcohol-Exposed Pregnancies — United States, 2011-2013
}

\author{
Patricia P. Green, $\mathrm{MSPH}^{1}$; Lela R. McKnight-Eily, $\mathrm{PhD}^{1}$; Cheryl H. Tan, $\mathrm{MPH}^{1}$; Roberto Mejia, $\mathrm{PhD}^{1}$; Clark H. Denny, $\mathrm{PhD}^{1}$
}

On February 2, 2016, this report was posted as an MMWR Early Release on the MMWR website (http://www.cdc.gov/mmwr).

\section{Abstract}

Background: Alcohol is a teratogen. ${ }^{*}$ Prenatal alcohol exposure is associated with a range of adverse reproductive outcomes and can cause fetal alcohol spectrum disorders (FASDs) characterized by lifelong physical, behavioral, and intellectual disabilities. FASDs are completely preventable if a woman does not drink alcohol while pregnant.

Methods: CDC analyzed data from the 2011-2013 National Survey of Family Growth to generate U.S. prevalence estimates of risk for an alcohol-exposed pregnancy for 4,303 nonpregnant, nonsterile women aged 15-44 years, by selected demographic and behavioral factors. A woman was considered at risk for an alcohol-exposed pregnancy during the past month if she had sex with a male, drank any alcohol, and did not (and her partner did not with her) use contraception in the past month; was not sterile; and had a partner (or partners) not known to be sterile.

Results: The weighted prevalence of alcohol-exposed pregnancy risk among U.S. women aged 15-44 years was 7.3\%. During a 1-month period, approximately 3.3 million women in the United States were at risk for an alcohol-exposed pregnancy.

Conclusions and Implications for Public Health Practice: Alcohol use in pregnancy is associated with low birthweight, preterm birth, birth defects, and developmental disabilities. Women of reproductive age should be informed of the risks of alcohol use during pregnancy, and contraception should be recommended, as appropriate, for women who do not want to become pregnant. Women wanting a pregnancy should be advised to stop drinking at the same time contraception is discontinued. Health care providers should advise women not to drink at all if they are pregnant or there is any chance they might be pregnant. Alcohol misuse screening and behavioral counseling (also known as alcohol screening and brief intervention) is recommended for all adults in primary care, including reproductive-aged and pregnant women, as an evidenced-based approach to reducing alcohol consumption among persons who consume alcohol in excess of the recommended guidelines.

\section{Introduction}

Alcohol use during pregnancy is associated with a range of complications and poor reproductive outcomes and can cause fetal alcohol spectrum disorders (FASDs), which are characterized by lifelong physical, behavioral, and intellectual disabilities (1-3). The estimated prevalence of FASDs, based on a community study of first grade students in the United States, ranges from $2 \%$ to $5 \%$ (4). FASDs are completely preventable if a woman does not drink alcohol at any time while she is pregnant.

In 2010, the cost of excessive alcohol use in the United States was $\$ 249$ billion, including $\$ 5.5$ billion in costs related to drinking while pregnant (5). Pregnancy-related costs include increased health care needs and lost productivity, as well as subsequent costs, such as special education for children with an FASD (5). Lifetime cost for an infant with fetal alcohol syndrome (FAS), a single disorder within the FASD continuum, has been estimated to be $\$ 2$ million (G).

\footnotetext{
*An agent that causes developmental disabilities.
}

The 2015-2020 Dietary Guidelines for Americans recommend that adults who choose to drink should do so in moderation: up to one drink per day for women and up to two drinks per day for men ( 7 ). However, these guidelines also recommend that some populations not consume any alcohol, including pregnant women and women who might be pregnant, as well as persons younger than the legal drinking age of 21 years $(7) .{ }^{\dagger}$ In 2005 , the U.S. Surgeon General released an updated advisory to women to raise awareness about FASDs (8). The advisory called for pregnant women and women considering pregnancy to abstain from drinking alcohol to reduce their risk for an alcohol-exposed pregnancy. Despite these known risks and warnings, a recent CDC study of alcohol use among reproductive-aged women found that $10.2 \%$ of pregnant women reported drinking any amount of alcohol during the past month and $3.1 \%$ reported that they binge drank (consumed four or more drinks on one occasion) (9).

\footnotetext{
$\dagger$ This is the legal drinking age in 50 U.S. states (https://alcoholpolicy.niaaa.nih. gov/the_1984_national_minimum_drinking_age_act_2.html). 
Approximately half of all pregnancies in the United States are unplanned (10), and alcohol-related fetal harm can occur in early pregnancy, before a woman recognizes that she is pregnant. Therefore, the best time to assess alcohol consumption and inform women about health consequences to them and their child is before pregnancy. Multiple organizations and groups advise women not to drink if they are or might be pregnant $(8,11-15)$. The American College of Obstetricians and Gynecologists (ACOG) and the U.S. Preventive Services Task Force both recommend routine alcohol screening and brief counseling (intervention) in primary care settings $(11,12)$. ACOG also recommends annual alcohol-use screening for all women seeking obstetric or gynecologic care and for women within the first trimester of pregnancy, as well as provision of information about risks of drinking during pregnancy (11). CDC analyzed data on female participants in the 2011-2013 National Survey of Family Growth (NSFG) to estimate the national prevalence of alcohol-exposed pregnancy risk among nonpregnant women in the United States and to identify characteristics of women at risk for an alcohol-exposed pregnancy.

\section{Methods}

NSFG uses a multistage probability-based, nationally representative sample of the household population of males and females, aged 15-44 years. Data collected from women during September 2011-September 2013 were analyzed for this report. The response rate for females included in the 2011-2013 NSFG was 73.4\%. Statistical design, interviewing, and data processing of the 2011-2013 NSFG were conducted by the University of Michigan's Institute for Social Research, under a contract with the National Center for Health Statistics, in collaboration with the center’s NSFG team. ${ }^{\S}$ Since NSFG data were obtained using a complex multistage probability cluster sample design, CDC used 2011-2013 NSFG data weighted to reflect the female household population of the United States in July 2012, the midpoint of data collection.

Prevalence estimates of risk for an alcohol-exposed pregnancy and associated $95 \%$ confidence intervals (CIs) were calculated for 4,303 nonpregnant, nonsterile women aged 15-44 years, stratified by age, race/ethnicity, marital status, education, number of live births, and smoking status. A woman was considered to be at risk for an alcohol-exposed pregnancy if she 1) had vaginal sex with a male during the past 4 weeks, 2) drank alcohol in any amount during the past 30 days, 3) did not (and her partner did not with her) use contraception during the month before the interview, and 4) was not sterile and she did not have a partner (or partners) known to be sterile (Figure 1). An additional, weighted analysis was conducted to

\footnotetext{
$\overline{\$}$ http://www.cdc.gov/nchs/data/nsfg/NSFG_2011-2013_UserGuide_MainText.pdf.
}

determine whether alcohol consumption differed on the basis of pregnancy desire, sexual activity, and contraception status. A woman was considered to desire pregnancy if she was having sex without using contraception in the month of the interview, and she reported that the reason for not using contraception was that either she or her partner wanted to become pregnant as soon as possible. The prevalence of any alcohol consumption during the past 30 days and $95 \%$ CIs were estimated for four groups: 1) women wanting to become pregnant as soon as possible who had sex with a man without using contraception, 2) women not wanting to become pregnant as soon as possible who had sex with a man without using contraception, 3) women who had sex using contraception or had a sterile partner, and 4) women who did not have sex with a man.

\section{Results}

Among nonpregnant, nonsterile U.S. women aged 15-44 years, the weighted alcohol-exposed pregnancy risk prevalence was $7.3 \%$ during a 1 -month period (Table). The risk for alcohol-exposed pregnancy differed significantly by age, and was highest among women aged $25-29$ years $(10.4 \%)$ and lowest among women aged $15-20$ years $(2.2 \%)$. The risk for alcohol-exposed pregnancy was also higher among women who were married $(11.7 \%)$ or cohabiting $(13.6 \%)$, compared with single women $(2.3 \%)$; among women who had one live birth (13.6\%), compared with women with no live births $(5.8 \%)$ or with two or more live births $(6.0 \%)$; and among women who were current smokers $(10.7 \%)$, compared with nonsmokers (6.0\%). The prevalence of alcohol-exposed pregnancy risk was positively associated with level of education, but did not differ by race/ethnicity.

The prevalence of alcohol use was similar among the three subgroups of sexually active women, ranging from $65.9 \%$ to $74.3 \%$, and did not differ by pregnancy desire (Figure 2). Women who reported not having sex with a male during the preceding 4 weeks had the lowest prevalence of alcohol use $(50.7 \%, \mathrm{CI}=45.6-55.8)$.

\section{Conclusions and Comments}

Alcohol is a known teratogen that can cause adverse reproductive outcomes for women, and serious, lifelong problems for a person exposed to it prenatally. These risks occur throughout pregnancy, including the period before a woman knows that

\footnotetext{
Tregnancy desire was assessed by the following questions: "Is the reason you are not using a method of birth control now because you, yourself, want to become pregnant as soon as possible?" (Response options: Yes, No, Refused, and Don't Know); and "Your partner, does he want you to become pregnant as soon as possible?” (Response options: Inapplicable, Yes, No, Refused, Don't Know, and No Current Partner [if volunteered]). A woman was desiring pregnancy if she reported that either she or her partner wanted to become pregnant as soon as possible.
} 
FIGURE 1. Identification of women aged 15-44 years at risk for an alcohol-exposed pregnancy (AEP) - National Survey of Family Growth, United States, 2011-2013*,†

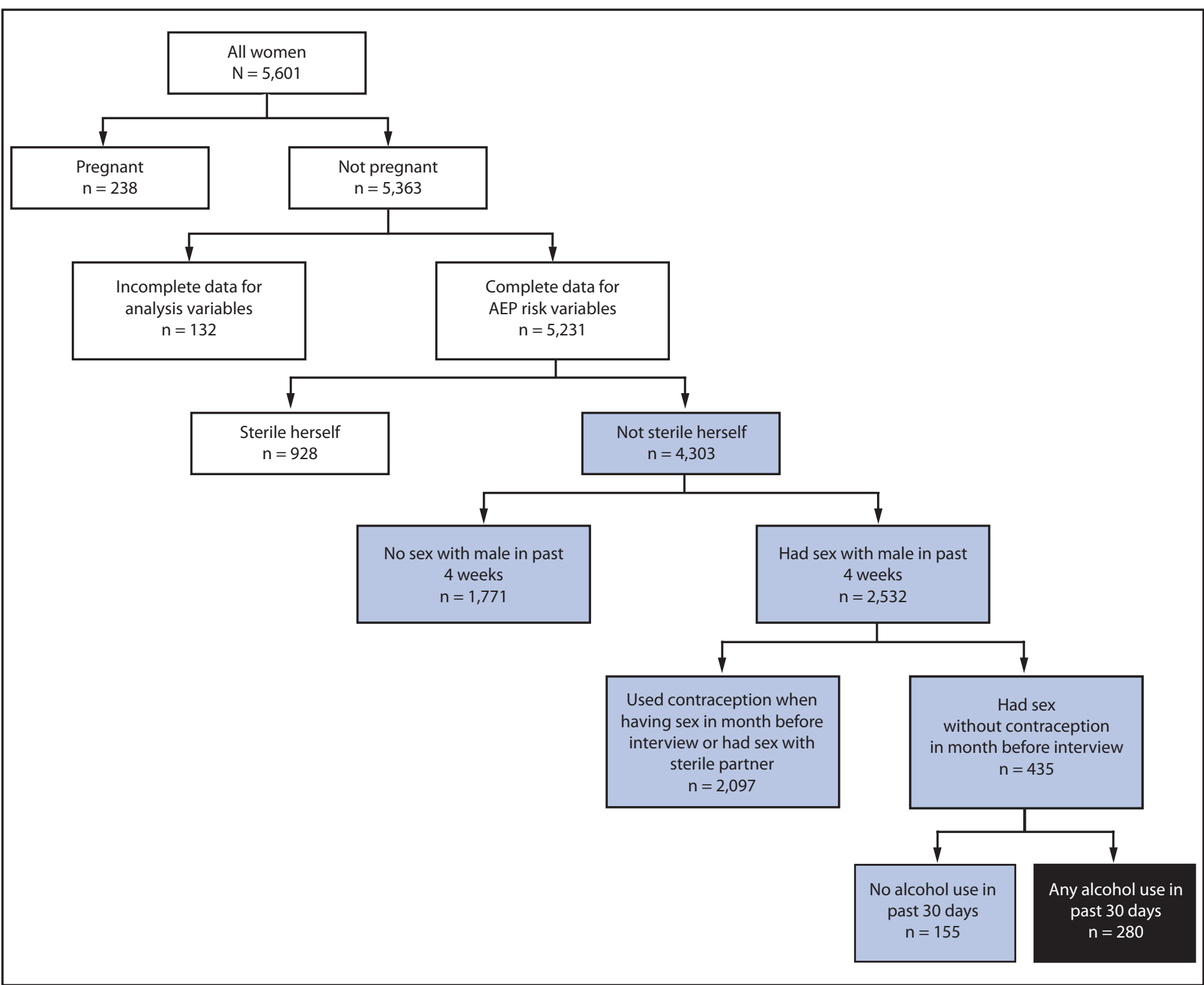

* Numbers are unweighted.

† Shaded boxes indicate women included in this study; the black box indicates women at risk for an alcohol-exposed pregnancy.

she is pregnant (16). All types of alcohol are harmful. To help prevent adverse consequences of alcohol consumption during pregnancy, health care providers should discuss and recommend, as appropriate, available contraception methods, ${ }^{* *}$ including condoms to protect against sexually transmitted diseases, to women who are sexually active and drink alcohol.

Reasons for some of the associations found in this study are unknown. One possible reason why married or cohabiting women were more likely than single women to be at risk for an alcohol-exposed pregnancy is that they might be less likely to use contraception. The risk for an alcohol-exposed pregnancy was most likely lowest among women with less than a high school diploma because most of them were aged $<21$ years, a population less likely to drink. The higher risk for an alcoholexposed pregnancy among smokers might be associated, in part, with smokers being more likely to drink alcohol. Health risk behaviors including excessive alcohol use and cigarette smoking can co-occur (17).

\footnotetext{
** http://www.cdc.gov/reproductivehealth/unintendedpregnancy/contraception.htm.
} 
TABLE. Prevalence estimates of risk for alcohol-exposed pregnancy among nonpregnant, nonsterile women of childbearing age, by selected characteristics - National Survey of Family Growth, United States, 2011-2013

\begin{tabular}{|c|c|c|c|c|}
\hline Characteristic & $\begin{array}{l}\text { Numerator, } \\
\text { unweighted }\end{array}$ & $\begin{array}{l}\text { Denominator, } \\
\text { unweighted }\end{array}$ & $\begin{array}{c}\text { Prevalence, } \\
\text { weighted } \\
\%(95 \% \mathrm{Cl})\end{array}$ & $\begin{array}{c}\text { Chi-square } \\
\text { p-value }\end{array}$ \\
\hline Overall & 280 & 4,303 & $7.3(6.2-8.6)^{*}$ & \\
\hline \multicolumn{5}{|l|}{ Age group (yrs) } \\
\hline $15-20$ & 25 & 1,148 & $2.2(1.2-3.9)$ & $<0.001$ \\
\hline $21-24$ & 51 & 688 & $7.9(5.5-11.1)$ & \\
\hline $25-29$ & 69 & 871 & $10.4(7.2-14.6)$ & \\
\hline 30-34 & 62 & 681 & $9.2(6.4-13.0)$ & \\
\hline 35-39 & 38 & 507 & $9.1(5.8-14.0)$ & \\
\hline 40-44 & 35 & 408 & $7.7(5.0-11.5)$ & \\
\hline \multicolumn{5}{|l|}{ Race/Ethnicity } \\
\hline $\begin{array}{l}\text { White only, } \\
\text { non-Hispanic }\end{array}$ & 138 & 1,963 & $8.2(6.4-10.4)$ & 0.352 \\
\hline $\begin{array}{l}\text { Black only, } \\
\text { non-Hispanic }\end{array}$ & 63 & 856 & $6.5(4.8-8.7)$ & \\
\hline Hispanic & 65 & 1,105 & $6.4(4.3-9.5)$ & \\
\hline $\begin{array}{l}\text { Other, } \\
\text { non-Hispanic }\end{array}$ & 14 & 379 & $4.8(2.8-8.2)$ & \\
\hline \multicolumn{5}{|l|}{ Marital status } \\
\hline Married & 118 & 1,164 & $11.7(9.1-14.8)$ & $<0.001$ \\
\hline Cohabiting & 67 & 551 & $13.6(9.2-19.8)$ & \\
\hline Single & 75 & 2,241 & $2.3(1.7-3.3)$ & \\
\hline $\begin{array}{l}\text { Divorced/ } \\
\text { Separated/ } \\
\text { Widowed }\end{array}$ & 20 & 347 & $5.2(3.0-9.1)$ & \\
\hline \multicolumn{5}{|c|}{ Education: highest degree received } \\
\hline $\begin{array}{l}\text { Less than high } \\
\text { school }\end{array}$ & 32 & 991 & $3.4(2.0-5.6)$ & 0.002 \\
\hline $\begin{array}{l}\text { High school } \\
\text { diploma }\end{array}$ & 78 & 1,054 & $8.6(6.0-12.1)$ & \\
\hline $\begin{array}{l}\text { Some college/ } \\
\text { Associate's }\end{array}$ & 109 & 1,290 & $7.7(5.8-10.1)$ & \\
\hline $\begin{array}{l}\text { Bachelor's or } \\
\text { greater }\end{array}$ & 61 & 968 & $8.7(6.0-12.3)$ & \\
\hline \multicolumn{5}{|c|}{ Number of live births } \\
\hline None & 109 & 2,232 & $5.8(4.2-8.1)$ & 0.003 \\
\hline One & 90 & 862 & $13.6(10.1-18.0)$ & \\
\hline Two or more & 81 & 1,209 & $6.0(4.3-8.1)$ & \\
\hline \multicolumn{5}{|c|}{ Smoking status past 12 months } \\
\hline Nonsmoker & 162 & 3,113 & $6.0(4.7-7.7)$ & 0.028 \\
\hline Former smoker & 34 & 350 & $9.3(6.4-13.5)$ & \\
\hline Current smoker & 84 & 840 & $10.7(7.6-14.8)$ & \\
\hline
\end{tabular}

Abbreviations: $\mathrm{Cl}=$ confidence interval; $\mathrm{SE}=$ standard error.

* Weighted numerator $=3,361,445$.

The current study found that approximately 3.3 million women aged 15-44 years reported drinking alcohol in the past month even though they had sex and did not use contraception, and thus were at risk for an alcohol-exposed pregnancy. Raising awareness about the dangers of alcohol use among reproductive-aged women is important, especially if contraception is not being used. This study also reinforces the importance of routinely screening women of reproductive age for alcohol use, and providing intervention before pregnancy. Health care professionals need to advise women who want to become pregnant and have discontinued contraception to stop drinking alcohol. These efforts might facilitate progress toward the Healthy People 2020 objective to increase alcohol abstinence among pregnant women from $89.4 \%$ to $98.3 \%$ (14).

The U.S. Preventive Services Task Force recommends alcohol misuse screening and behavioral counseling (also known as alcohol screening and brief intervention [alcohol SBI]) for all adults in primary care, including pregnant women (12). Alcohol SBI involves screening for alcohol misuse using a recommended and valid instrument or screening question, and then conducting a brief (typically 6-15-minute) intervention or counseling session if a person screens positive. The brief intervention ascertains whether the person wants to reduce their drinking and places their behavior in the context of their overall health. Finally, a small percentage of persons with indications of alcohol dependence are referred for more specialized treatment (12).

Systematic reviews and a meta-analysis have shown that alcohol SBI is effective in reducing alcohol consumption among women of childbearing age who were included in studies of both men and women (18-20), and in studies limited to women of childbearing age $(21,22)$. Among women of childbearing age specifically, a subanalysis of a Trial for Early Alcohol Treatment (Project TrEAT) ${ }^{\dagger \dagger}$ conducted at follow-up 48 months later found reductions in mean alcohol intake of $48 \%$ (from 14 to 7.5 drinks per week), and reductions in the prevalence of binge drinking (from 93\% to 68\%) and number of binge drinking episodes during the previous 30 days (from five to three) in the treatment group ( $\mathrm{n}=103)$, compared with baseline, and a $68 \%$ reduction in the number of women who drank more than 13 drinks per week, which was more of a reduction than in the control group $(n=102)(21)$. Alcohol SBI was found to be significantly associated with maintaining abstinence in a sample of 143 pregnant women at high risk; $86 \%$ of women in the intervention group reported continued abstinence, compared with $72 \%$ in the control group (23).

Although alcohol SBI is routinely recommended in primary care and is effective in reducing excessive alcohol use, a previous CDC study reported that only one in six U.S. adults reported ever talking to a health professional about alcohol (24). This is particularly concerning for women of childbearing age, given the serious consequences associated with drinking alcohol while pregnant.

Behavior change is complex and must occur across multiple domains, from the individual to broader systems, to be effective. Thus, primary care interventions are necessary, but not adequate to change population health (25). CDC has developed a guide

\footnotetext{
$\dagger$ Project TrEAT included a large sample of women aged 18-40 years, and was conducted in the offices of 64 community-based primary care physicians from $10 \mathrm{Wisconsin}$ counties. The intervention involved two visits with a primary care provider, follow-up phone calls, feedback about health behaviors, and other information.
} 
FIGURE 2. Estimated prevalence* of any alcohol consumption in the past 30 days among nonpregnant, nonsterile women aged $15-44$ years, by pregnancy desire, sexual activity, and contraception use ${ }^{\dagger}$ status - National Survey of Family Growth, United States, 2011-2013

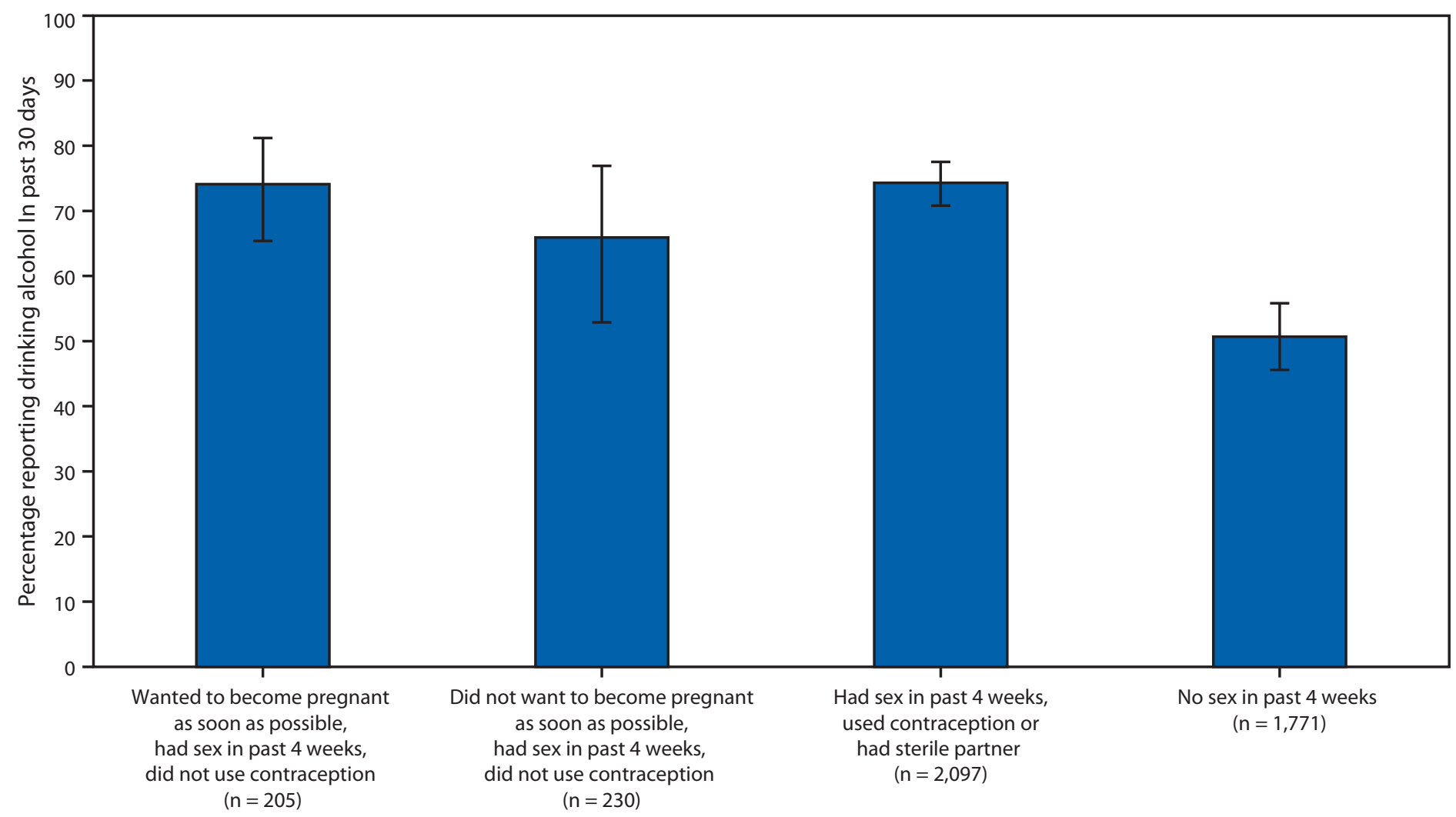

* With 95\% confidence intervals indicated with error bars.

${ }^{\dagger}$ In month before interview month.

to help clinical practices systematically implement alcohol SBI (26). The Affordable Care Act requires coverage of the U.S. Preventive Services Task Force B-level recommended clinical preventive services such as alcohol SBI, without copayment. $\$ \$$ Coupling alcohol SBI with population-based strategies recommended by the Community Preventive Services Task Force to reduce excessive alcohol use might have greater impact. These recommended population-based strategies include electronic SBI (e.g., use of computers, telephones, or mobile devices to deliver components of alcohol SBI99) that can occur within clinical or other environments, as well as enhanced enforcement of laws prohibiting sale of alcohol to minors. ${ }^{* * *}$

\footnotetext{
$\$ \$$ The Patient Protection and Affordable Care Act of 2010 requires that nongrandfathered private health plans provide coverage without cost-sharing for services that have in effect an "A" or "B" recommendation from the U.S. Preventive Services Task Force (USPSTF). Because USPSTF issued a "B" recommendation for alcohol SBI in adults aged $\geq 18$ years, this must be covered by such plans, Section 1001 of the Patient Protection and Affordable Care Act, Public Law 111-148, 2010 (http://www.gpo.gov/fdsys/pkg/PLAW111 publ148/html/PLAW-111publ148.htm).

$99 \mathrm{http} / /$ www.thecommunityguide.org/alcohol/eSBI.html.

*** http://www.thecommunityguide.org/alcohol/lawsprohibitingsales.html.
}

The findings in this report are subject to at least three limitations. First, NSFG data are based on self-reporting and are subject to respondent recall bias. Second, social desirability bias might have resulted in an underestimation of risk for alcohol-exposed pregnancy; however, questions on alcohol consumption were asked as part of the audio, computer-assisted self-interview, a data collection method that can reduce this bias. Finally, the timeframes of variables used to define risk for alcohol-exposed pregnancy in this study did not completely align. Specifically, contraception use was measured in the calendar month before the interview but the other variables were measured in the 4 weeks or 30 days before the interview. Fewer than $6 \%$ of nonpregnant, nonsterile women changed their contraceptive practices between the month of interview and the calendar month before the interview, suggesting that the contraception measure used in this study is a reasonable approximation of current contraceptive practices, despite the slight misalignment in timeframes.

Alcohol SBI by a health care provider, combined with assessment of a woman's contraceptive needs, can help reduce a woman's risk for an alcohol-exposed pregnancy. Some women might benefit from extended counseling or an increased 


\section{Key Points}

- Alcohol use during pregnancy is associated with a range of adverse reproductive outcomes and can cause fetal alcohol spectrum disorders, characterized by lifelong physical, behavioral, and intellectual disabilities.

- Approximately 3.3 million U.S. women aged 15-44 years who were not pregnant and not sterile were at risk for an alcohol-exposed pregnancy during 2011-2013.

- Three in four women who wanted to get pregnant as soon as possible reported drinking alcohol, putting them at risk for an alcohol-exposed pregnancy. Any sexually active woman of reproductive age who is drinking alcohol and not using birth control is at risk for an alcohol-exposed pregnancy.

- A developing baby can be exposed to alcohol before a woman knows she is pregnant. Approximately half of all pregnancies in the United States are unplanned. Even if a pregnancy is planned, a woman probably will not know she is pregnant until she is $4-6$ weeks into the pregnancy.

- Alcohol screening and brief intervention is recommended for all adults, including pregnant women. This clinical service is effective, inexpensive, and can be accomplished in 6-15 minutes, although follow-up sessions might be needed. Health care providers should advise women not to drink at all if they are pregnant or might be pregnant.

- To help prevent adverse consequences of alcohol consumption during pregnancy, health care providers should discuss and recommend, as appropriate, available contraception methods to women who are sexually active and drink alcohol. They should also screen them for excessive alcohol use and counsel or refer them as needed regarding their overall health.

- Additional information is available at http://www.cdc. gov/vitalsigns.

number of counseling sessions, and additional evidence-based interventions (27) might be needed to help them modify their drinking or contraception behaviors, or both. A comprehensive approach that greatly increases alcohol SBI, extended counseling when needed, and population-based strategies should reduce the risk for alcohol-exposed pregnancy and the concomitant negative health outcomes over time.

\section{Acknowledgments}

National Survey of Family Growth Team, National Center for Health Statistics, CDC, Hyattsville, Maryland; Jacquelyn Bertrand, National Center on Birth Defects and Developmental Disabilities, CDC.

${ }^{1}$ Division of Birth Defects and Developmental Disabilities, National Center on Birth Defects and Developmental Disabilities, CDC.

Corresponding author: Patricia P. Green, PAP5@cdc.gov, 404-498-3953.

\section{References}

1. Sokol RJ, Delaney-Black V, Nordstrom B. Fetal alcohol spectrum disorder. JAMA 2003;290:2996-9. http://dx.doi.org/10.1001/ jama.290.22.2996.

2. Bailey BA, Sokol RJ. Prenatal alcohol exposure and miscarriage, stillbirth, preterm delivery, and sudden infant death syndrome. Alcohol Res Health 2011;34:86-91.

3. Streissguth AP, Bookstein FL, Barr HM, Sampson PD, O’Malley K, Young JK. Risk factors for adverse life outcomes in fetal alcohol syndrome and fetal alcohol effects. J Dev Behav Pediatr 2004;25:228-38. http:// dx.doi.org/10.1097/00004703-200408000-00002.

4. May PA, Baete A, Russo J, et al. Prevalence and characteristics of fetal alcohol spectrum disorders. Pediatrics 2014;134:855-66. http://dx.doi. org/10.1542/peds.2013-3319.

5. Sacks JJ, Gonzales KR, Bouchery EE, Tomedi LE, Brewer RD. 2010 National and state costs of excessive alcohol consumption. Am J Prev Med 2015;49:e73-9. http://dx.doi.org/10.1016/j.amepre.2015.05.031.

6. Lupton C, Burd L, Harwood R. Cost of fetal alcohol spectrum disorders. Am J Med Genet C Semin Med Genet 2004;127C:42-50. http://dx.doi. org/10.1002/ajmg.c.30015.

7. US Department of Health and Human Services and US Department of Agriculture. 2015-2020 Dietary Guidelines for Americans. 8th ed. Washington, DC: US Department of Health and Human Services and US Department of Agriculture; 2015. http://health.gov/ dietaryguidelines/2015/guidelines.

8. US Department of Health and Human Services. US Surgeon General releases advisory on alcohol use in pregnancy. Washington, DC: US Department of Health and Human Services; 2005. https://wayback. archive-it.org/3926/20140421162517/http://www.surgeongeneral.gov/ news/2005/02/sg02222005.html.

9. Tan CH, Denny CH, Cheal NE, Sniezek JE, Kanny D. Alcohol use and binge drinking among women of childbearing age-United States, 2011-2013. MMWR Morb Mortal Wkly Rep 2015;64:1042-6. http:// dx.doi.org/10.15585/mmwr.mm6437a3.

10. Finer LB, Zolna MR. Shifts in intended and unintended pregnancies in the United States, 2001-2008. Am J Public Health 2014;104(Suppl 1):S43-8. http://dx.doi.org/10.2105/AJPH.2013.301416.

11. American College of Obstetricians and Gynecologists Committee on Health Care for Underserved Women. At-risk drinking and alcohol dependence: obstetric and gynecology implications. Committee Opinion No. 496; 2011 (Reaffirmed 2013). http://www.acog.org/ Resources-And-Publications/Committee-Opinions/Committee-onHealth-Care-for-Underserved-Women/At-Risk-Drinking-and-AlcoholDependence-Obstetric-and-Gynecologic-Implications.

12. Moyer VA; Preventive Services Task Force. Screening and behavioral counseling interventions in primary care to reduce alcohol misuse: U.S. preventive services task force recommendation statement. Ann Intern Med 2013;159:210-8.

13. CDC. Vital Signs: binge drinking. A serious under-recognized problem among women and girls. Atlanta, GA: US Department of Health and Human Services; 2013. http://www.cdc.gov/vitalsigns/ bingedrinkingfemale. 
14. US Department of Health and Human Services. Healthy People 2020: maternal, infant, and child health. Washington, DC: US Department of Health and Human Services; 2015. http://www.healthypeople.gov/2020/ topics-objectives/topic/maternal-infant-and-child-health/objectives.

15. Williams JF, Smith VC; Committee on substance abuse. Fetal alcohol spectrum disorders. Pediatrics 2015;136:e1395-406. http://dx.doi. org/10.1542/peds.2015-3113.

16. Floyd RL, Decouflé P, Hungerford DW. Alcohol use prior to pregnancy recognition. Am J Prev Med 1999;17:101-7. http://dx.doi.org/10.1016/ S0749-3797(99)00059-8.

17. Skalamera J, Hummer RA. Educational attainment and the clustering of health-related behavior among U.S. young adults. Prev Med 2015;S0091-7435(15)00384.

18. Ballesteros J, González-Pinto A, Querejeta I, Ariño J. Brief interventions for hazardous drinkers delivered in primary care are equally effective in men and women. Addiction 2004;99:103-8. http://dx.doi. org/10.1111/j.1360-0443.2004.00499.x.

19. Bertholet N, Daeppen JB, Wietlisbach V, Fleming M, Burnand B. Reduction of alcohol consumption by brief alcohol intervention in primary care: systematic review and meta-analysis. Arch Intern Med 2005;165:986-95. http://dx.doi.org/10.1001/archinte.165.9.986.

20. Jonas DE, Garbutt JC, Amick HR, Brown JM, et al. Behavioral counseling after screening for alcohol misuse in primary care: a systematic review and meta-analysis for the US Preventive Services Task Force. Ann Intern Med 2012;157:645-54.
21. Manwell LB, Fleming MF, Mundt MP, Stauffacher EA, Barry KL. Treatment of problem alcohol use in women of childbearing age: results of a brief intervention trial. Alcohol Clin Exp Res 2000;24:1517-24. http://dx.doi.org/10.1111/j.1530-0277.2000.tb04570.x.

22. Delrahim-Howlett K, Chambers CD, ClappJD, et al. Web-based assessment and brief intervention for alcohol use in women of childbearing potential: a report of the primary findings. Alcohol Clin Exp Res 2011;35:1331-8. http://dx.doi.org/10.1111/j.1530-0277.2011.01469.x.

23. Chang G, Wilkins-Haug L, Berman S, Goetz MA. Brief intervention for alcohol use in pregnancy: a randomized trial. Addiction 1999;94:1499508. http://dx.doi.org/10.1046/j.1360-0443.1999.941014996.x.

24. McKnight-Eily LR, Liu Y, Brewer RD, et al. Vital signs: communication between health professionals and their patients about alcohol use-44 states and the District of Columbia, 2011. MMWR Morb Mortal Wkly Rep 2014;63:16-22.

25. McNellis RJ, Ory MG, Lin JS, O'Connor EA. Standards of evidence for behavioral counseling recommendations. Am J Prev Med 2015; 49(Suppl 2):S150-7.

26. CDC. Planning and implementing screening and brief intervention for risky alcohol use. Atlanta, GA: US Department of Health and Human Services, CDC; 2014. http://www.cdc.gov/ncbddd/fasd/documents/ alcoholsbiimplementationguide.pdf.

27. Floyd RL, Sobell M, Velasquez MM, et al.; Project CHOICES Efficacy Study Group. Preventing alcohol-exposed pregnancies: a randomized controlled trial. Am J Prev Med 2007;32:1-10. http://dx.doi. org/10.1016/j.amepre.2006.08.028. 